\title{
Analysis of the impact of wind on fuel consumption and emissions of harmful exhaust gas compounds on the selected flight route
}

The article discusses the issue of the impact of wind force and direction on fuel consumption and the emission of harmful exhaust gases on the selected flight route. The focus was on percentage changes in fuel consumption and emissions of individual harmful exhaust gas compounds depending on the wind speed and the direction from which it interacts with the aircraft. The analysis was carried out for three different flight levels, in order to compare changes in fuel consumption and emissions also in terms of flight altitude, however the following article focuses only on one level-FL240.

Key words: LTO cycle, impact of wind, emission, fuel consumption

\section{Introduction}

One of the most modern and the most dynamically developing branches of transport is air transport. Popularity in the selection of these is increasing along with the demand for the transport of goods and people, which is becoming bigger each year. An increase in the wealth of societies, a greater interest in travel and a short flight time as well as a high safety index cause an increase in the number of air connections around the world. According to Airbus forecasts, air traffic doubles every 15 years [2]. The number of flights increased by $80 \%$ between 1990 and 2014, and it is predicted that by 2035 it will increase by $45 \%$ [4]. The growing number of air connections has a huge impact on the environment and climate change. Aircrafts, in comparison to the other means of transport, emit very large amounts of harmful compounds contained in the exhaust gases, and also generate a high degree of noise, which is particularly undesirable in near-center areas. The following is shown forecasted emission levels of harmful compounds and the forecasted number of flights by 2035 (Fig. 1). Over the past few years, more and more have been heard about the increasing share of $\mathrm{CO}_{2}$ in the atmosphere and about growing air pollution, which may have disastrous consequences in the future. For example, the total emission of nitrogen oxides in the exhaust gas of aircrafts engines doubled between 1990 and 2014 and is expected to increase by $43 \%$ by 2035 [4].

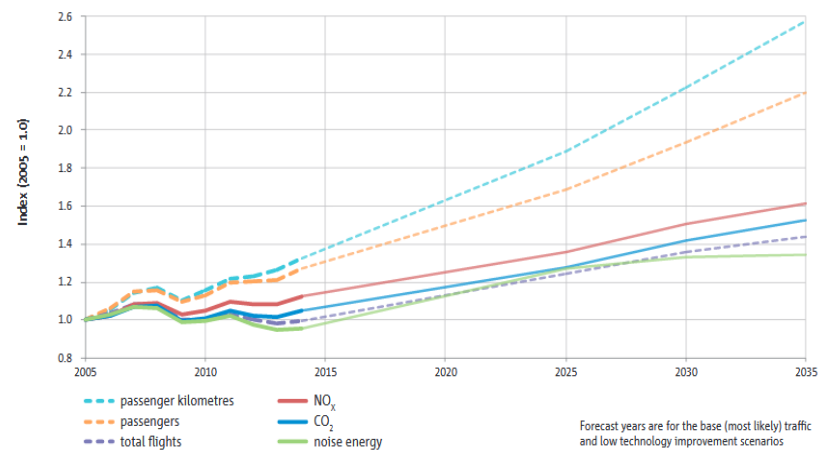

Fig. 1. Noise and emissions forecast [9]
Emission of carbon dioxide between 1990 and 2005 increased by $77 \%$, and between 2005 and 2014 by only $5 \%$. On the other hand, the increase in $\mathrm{CO}_{2}$ emissions by $44 \%$ is estimated between 2005 and 2035 [4]. Considering the aviation sector, which causes a huge amounts of toxic compounds and carbon dioxide during air operations, it is worth analyzing what factors affect the emission of harmful compounds and how it will change depending on the flight parameters. It is known that the longer is the flight time, the more airborne substances are emitted into the atmosphere. It is therefore worth checking how the strength and direction of the wind will affect the speed of the aircraft's flight, shortening or lengthening the flight time, and thus also the emission of harmful exhaust compounds and fuel consumption. For this reason, the following article analyzes different variants of wind direction and force that affects the flight of an aircraft.

The analysis was carried out for three selected flight levels, in order to compare emissions of harmful exhaust compounds and fuel consumption also depending on the flight level, however the following article focuses only on one altitude. The analyzed flight is a flight at FL240 on the Rzeszow-Szczecin route with Dassault Falcon 100 aircraft, equipped with two Garrett TFE731-2-2B engines.

\section{Legal regulations concerning the emission of harmful exhaust gases}

Along with the growth of air traffic, more and more standards concerning exhaust emissions are imposed, however, tests and measurements of the emissivity of engines focus mainly on operations around the airfield, which may have the greatest impact on people and the environment. The main harmful compounds emitted by turbine aircraft engines are carbon dioxide $\left(\mathrm{CO}_{2}\right)$, carbon monoxides $(\mathrm{CO})$, hydrocarbons $(\mathrm{HC})$, nitrogen oxides $\left(\mathrm{NO}_{\mathrm{x}}\right)$ and particulate matter (PM) $[9,10]$. The size of the emission depends on the type of fuel used, the type of engine, the type of aircraft and its mass, as well as on the flight conditions such as altitude, speed and level of thrust [7].

Operations performed by the aircraft can be divided into two groups [7]: 
a) operations carried out in the area of the aerodrome: take-off, climb, landing and taxi, which are carried out up to $3000 \mathrm{ft}$,

b) flight of the aircraft on the route: all operations performed by the aircraft above $3000 \mathrm{ft}$.

It is worth noting that the largest amount of toxic compounds is emitted in the upper atmosphere, at altitudes from 8 to $12 \mathrm{~km}$ above sea level, while only 5 to $10 \%$ of world fuel consumption takes place at altitudes not exceeding 1 $\mathrm{km}$ above sea level [9]. One of the tests of emission of harmful exhaust gases emitted by civil aircraft is the LTO (Landing and Take off) test. It focuses on operations performed by the aircraft up to the altitude of $3000 \mathrm{ft}$, and includes such operations as take-off, climb, landing and taxi (Fig. 2).

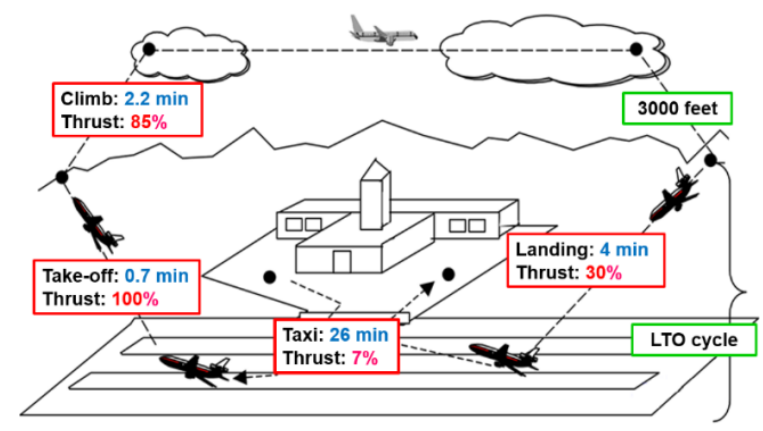

Fig. 2. Flight phases in the LTO cycle [11]

This test includes turbine engines which thrust is more than $27.6 \mathrm{kN}$. The duration of each test phase corresponds to the generalized time of a particular aircraft operation in real conditions for which a typical engine power setting has also been determined (Table 1). The duration of the whole test is about $30 \mathrm{~min}$ [5]. For the proper conduct of the LTO test it is also necessary to measure the average fuel flow rate given in $\mathrm{kg} / \mathrm{s}$, emission indexes expressed in $\mathrm{g} / \mathrm{kg}$ of used fuel for each harmful compound emitted by the engine and information on the measured smoke [13].

Table 1. Engine operating range during the LTO test [13]

\begin{tabular}{|c|c|c|}
\hline LTO work scope & Thrust setting & Phase duration [min] \\
\hline Take-off & $100 \%$ Foo & 0.7 \\
\hline Climb & $85 \%$ Foo & 2.2 \\
\hline Approach & $30 \%$ Foo & 4.0 \\
\hline Taxi & $7 \%$ Foo & 26.0 \\
\hline
\end{tabular}

The result obtained in the LTO test for a single cycle is the mass of the harmful compound per mass of fuel burnt, which is calculated according to the formula [5]:

$\mathrm{EPC}_{\mathrm{pol}, \text { mode }}=(\mathrm{TIM} / 60) \cdot(\mathrm{FFR} / 1000) \cdot \mathrm{EF} \cdot \mathrm{NE}$

where: $\mathrm{EPC}_{\mathrm{pol} \text {,mode }}-$ Emissions per cycle for a particular pollutant during a particular mode [lb/cycle], TIM - Time in Mode [min/cycle], FRR - Fuel Flow Rate [lb/hr], EF Emission Factor [lb/1000 lb], NE -Number of engines on the aircraft.

To calculate the total emission of a harmful compound it is necessary to sum up the emission value for all phases [5]:

$\mathrm{EPC}_{\text {total }}=\mathrm{EPC}_{\mathrm{pol}, \text { app }}+\mathrm{EPC}_{\mathrm{pol}, \text { taxi }}+\mathrm{EPC}_{\mathrm{pol}, \text { takeoff }}+\mathrm{EPC}_{\mathrm{pol}, \text { climb }}$
In order to calculate the total emissions of harmful compounds emitted during the entire flight of an aircraft, it is also necessary to calculate emissions in the cruising phase. Unfortunately, there are no standards specifying the emission limit values for individual toxic exhaust compounds, i.e. carbon monoxides, hydrocarbons and nitrogen oxides. Most studies on harmful emissions focus only on carbon dioxide emissions, which are almost linearly dependent on fuel consumption [10]. In order to accurately calculate the emission of harmful exhaust gas compounds in the inlet phase, it is necessary to determine emission factors for individual harmful exhaust gas compounds for the pass phase, including flight altitude as well as ambient temperature and pressure in the calculations. Data necessary to calculate emission factors these are emission factors for the LTO cycle in the throughput phase. This solution will allow to obtain coefficients that correspond to a given engine power and external conditions of the flight [8].

The following formulas will be used to determine the emission of harmful compounds:

$$
\begin{aligned}
\mathrm{E}_{\mathrm{CO}} & =\mathrm{EI}_{\mathrm{CO}} \cdot 10^{-3} \cdot \mathrm{K} \cdot \mathrm{SFC} \cdot \mathrm{t} \cdot \mathrm{l} \\
\mathrm{E}_{\mathrm{NO}_{\mathrm{x}}} & =\mathrm{EI}_{\mathrm{NO}_{\mathrm{x}}} \cdot 10^{-3} \cdot \mathrm{K} \cdot \mathrm{SFC} \cdot \mathrm{t} \cdot \mathrm{l} \\
\mathrm{E}_{\mathrm{HC}} & =\mathrm{EI}_{\mathrm{HC}} \cdot 10^{-3} \cdot \mathrm{K} \cdot \mathrm{SFC} \cdot \mathrm{t} \cdot \mathrm{l}
\end{aligned}
$$

where: $\mathrm{E}_{\mathrm{CO}} / \mathrm{E}_{\mathrm{NOx}} / \mathrm{E}_{\mathrm{HC}}-$ emission of individual substances $[\mathrm{kg}], \mathrm{EI}_{\mathrm{CO}} / \mathrm{EI}_{\mathrm{NOx}} / \mathrm{EI}_{\mathrm{HC}}-$ emission factors for individual substances, depending on the type of engine and the scope of their work $[\mathrm{g} / \mathrm{kg}], \mathrm{K}$ - engine thrust [N], SFC - unit fuel consumption $[\mathrm{kg} /(\mathrm{N} \cdot \mathrm{h})], \mathrm{t}$ - engine run time at a given thrust value $[\mathrm{h}], 1-$ number of engines on the aircraft.

In order to obtain emission factors of EI harmful compounds, it is necessary to depend them on the temperature, pressure and air humidity at a given cruising altitude:

$$
\begin{gathered}
\mathrm{EI}_{\mathrm{CO}}=\mathrm{EI}_{\text {COLTO }} \cdot \frac{\theta^{3.3}}{\delta^{1.02}} \\
\mathrm{EI}_{\mathrm{HC}}=\mathrm{EI}_{\mathrm{HCLTO}} \cdot \frac{\theta^{3.3}}{\delta^{1.02}} \\
\mathrm{EI}_{\mathrm{NO}_{\mathrm{x}}}=\mathrm{EI}_{\mathrm{NO}_{\mathrm{x}} \mathrm{LTO}} \cdot \sqrt{\frac{\delta^{1.02}}{\theta^{3.3}}} \cdot \mathrm{e}^{\mathrm{h}}
\end{gathered}
$$

where: $\mathrm{EI}_{\mathrm{CO}}, \mathrm{EI}_{\mathrm{HC}}, \mathrm{EI}_{\mathrm{NOx}}-\mathrm{CO}, \mathrm{HC}$ and $\mathrm{NO}_{\mathrm{x}}$ emission factors at a given altitude $[\mathrm{g} / \mathrm{kg}], \mathrm{EI}_{\text {COLto }}, \mathrm{EI}_{\text {HCLTO }}$, $\mathrm{EI}_{\mathrm{NOxLTO}}-\mathrm{CO}, \mathrm{HC}$ and $\mathrm{NO}_{\mathrm{x}}$ emission factors measured for LTO parameters $[\mathrm{g} / \mathrm{kg}]$.

To calculate the temperature, pressure and humidity coefficients, the following formulas should be used:

$\theta$ - temperature change coefficient [-]:

$$
\theta=\frac{\mathrm{T}_{\mathrm{c}}}{288.15 \mathrm{~K}}
$$

$\delta$ - pressure change coefficient [-]:

$$
\delta=\frac{\mathrm{p}_{\mathrm{c}}}{101325 \mathrm{~Pa}}
$$

$\mathrm{e}-$ Euler number $(\mathrm{e}=2.72)$

$\mathrm{h}-$ the air humidity factor depends on the altitude [-]:

$$
\mathrm{h}=-19 \cdot(\omega-0.00634)
$$

$\omega-$ specific humidity, 
that: $\omega=10^{-3} \cdot \mathrm{e}^{-0.0001426 \cdot(\mathrm{H}-12900)}$,

where $\mathrm{H}$ is the cruising altitude given in feet.

In turn, to determine the parameters of the environment at a given speed and flight altitude necessary to calculate the temperature and pressure change coefficients, use the dependence [8]:

$$
\begin{gathered}
\mathrm{T}_{\mathrm{c}}=\mathrm{T} \cdot\left(1+0.2 \cdot \mathrm{Ma}^{2}\right) \\
\mathrm{p}_{\mathrm{c}}=\mathrm{p} \cdot\left(1+0.2 \cdot \mathrm{Ma}^{2}\right)^{3.5}
\end{gathered}
$$

where: $\mathrm{T}_{\mathrm{c}}-$ total temperature $[\mathrm{K}], \mathrm{p}_{\mathrm{c}}-$ total pressure $[\mathrm{Pa}], \mathrm{T}$ - ambient temperature $[\mathrm{K}]$ at a given flight altitude (according to the standard atmosphere), $\mathrm{p}$ - ambient pressure [Pa] at a given flight altitude (according to the standard atmosphere), Ma - airplane speed [-].

To calculate $\mathrm{T}$ and $\mathrm{p}$, use the parameters of the reference atmosphere and the dependence between them. To determine the temperature at a given cruising altitude, a vertical temperature gradient of up to $11,000 \mathrm{~m}$ must be used, i.e. a temperature drop of 6.5 Kelvin for every kilometer of altitude, from the sea level, i.e equal to $288.15 \mathrm{~K}$. From $11,000 \mathrm{~m}$ up to $20,000 \mathrm{~m}$, the temperature is constant and amounts to $-56.5^{\circ} \mathrm{C}$. In the case of determining the pressure at a given flight altitude, use the formula [12]:

$$
\mathrm{p}=\mathrm{p}_{\mathrm{o}} \cdot\left(1-\frac{\mathrm{H}_{1}}{44300}\right)^{5.256}
$$

where: $\mathrm{p}_{\mathrm{o}}$ - pressure at sea level equal to $1013.25 \mathrm{hPa}, \mathrm{H}_{1}-$ flight altitude expressed in meters.

\section{Research methodology}

- In order to analyze the impact of wind on fuel consumption and emissions of harmful exhaust compounds, it was needed to make assumptions necessary to perform calculations. A few more important assumptions are presented below:

- For the purpose of determining the length of the route that the aircraft will defeat in relation to the ground during the climb to a specific cruising altitude, a climb angle of $10^{\circ}$ was assumed for the entire aircraft's climb phase. This angle was established on the basis of a list of the construction angles of selected Boeing aircraft [1].

- In order to calculate the emission of harmful exhaust gas compounds, i.e. hydrocarbons, carbon monoxides and nitrogen oxides, the same relationships as for the calculation of emission of harmful exhaust gas in the LTO test were used. Due to the lack of information about the emission factors of individual harmful exhaust gas compounds, the percentage setting of the engine thrust and the average fuel flow rate at the aircraft height above $3000 \mathrm{ft}$ (about $1000 \mathrm{~m}$ ) data used in the ICAO Database [6] were used for LTO tests the engine being analyzed. This means that for an aircraft altitude of over $3000 \mathrm{ft}$, the engine thrust setting is $85 \%$ of the nominal thrust. However, the average fuel flow rate is $0.173 \mathrm{~kg} / \mathrm{s}$ and used to calculate the fuel consumption during the climb phase.

- The flight time from the starting point to the ending point shall not take into account the effect of wind on the change of direction of flight and the course of the aircraft, which results in a longer journey and flight time. For this reason, in the analysis of the impact of wind force and direction on the speed of the aircraft flight, the wind component perpendicular to the direction of flight of the aircraft is not taken into account. It is assumed that the wind speed and assumed wind direction do not change during the entire flight phase.

- For the problem analysis, an engine thrust of $50 \%$ of the nominal thrust was assumed for the in-flight phase.

- In order to calculate the emission of harmful exhaust gases during the flight phase, it is necessary to know the emission factors of individual harmful compounds, which coefficients have not been determined by engine manufacturers or are not available to aircraft users. Therefore, the emission ratios of harmful compounds for individual phases of the LTO test and on their basis a graph was drawn up taking into account the degree of setting the engine thrust were used. On the basis of the trend line of a given graph, the estimated value of the emission factor of a specific harmful compound for the engine set-up equal to $50 \%$ of the nominal thrust was calculated.

- In order to determine the distance that the aircraft will travel to the ground during descent from a specific cruising altitude, a descent angle of $3^{\circ}$ is assumed for a landing approach operation starting at $500 \mathrm{ft}$ (approximately $152 \mathrm{~m}$ ). For the landing phase between the cruising altitude and the landing altitude of the landing approach, a descent angle of $10^{\circ}$ was assumed.

- To calculate emissions of harmful exhaust compounds, i.e. hydrocarbons, carbon monoxides and nitrogen oxides during the climb and landing phase, the same relation as in the case of calculating emissions of harmful exhaust gas in the LTO test has been applied. Due to the lack of information on the emission factors of individual harmful exhaust gas compounds, the percentage setting of the engine thrust and the average fuel flow rate at elevation and descent of the aircraft above $3000 \mathrm{ft}$ (about $1000 \mathrm{~m}$ ), the data contained in the ICAO Data Base [6] were used for LTO tests of the analyzed engine. This means that for an aircraft altitude of over $3000 \mathrm{ft}$, the engine thrust setting is $85 \%$ of the nominal thrust. However, the average fuel flow rate is $0.173 \mathrm{~kg} / \mathrm{s}$ and used to calculate the fuel consumption during the climb phase. However, for the landing phase starting at an altitude greater than $3000 \mathrm{ft}$, the engine thrust setting is $30 \%$ of the nominal thrust. The average fuel flow rate is 0.067 $\mathrm{kg} / \mathrm{s}$.

- For the purposes of the analyzes, a weak wind of $10 \mathrm{kt}$, a moderate wind of $25 \mathrm{kt}$ and a strong wind of $40 \mathrm{kt}$ was assumed.

- In order to make it easier to compare results and handle the cases of wind force and direction considered, the following designations were introduced:

Wind direction:

$\mathbf{P}$ - the wind blowing in the forehead of the aircraft,

$\mathbf{T}$ - wind blowing in the tail of the aircraft.

Angle of wind (towards the direction of flight of the aircraft):

1 - 0 degrees,

2 - 30 degrees, 


$$
\begin{aligned}
& \mathbf{3} \text { - } 45 \text { degrees, } \\
& \mathbf{4} \text { - } 60 \text { degrees. }
\end{aligned}
$$

The parameters of the selected aircraft and its engine are shown in Table 2 and 3.

Table 2. Dassault Falcon 100 aircraft performance (own elaboration based on [3])

\begin{tabular}{|l|c|}
\hline Range & $2446 \mathrm{~km}$ \\
\hline MTOW & $8500 \mathrm{~kg}$ \\
\hline BEM & $4880 \mathrm{~kg}$ \\
\hline Max cruising speed & $907 \mathrm{~km} / \mathrm{h}$ \\
\hline Max cruising altitude & $13716 \mathrm{~m}$ \\
\hline
\end{tabular}

Table 3. Parameters of the Garrett TFE731-2 engine (own elaboration based on [12])

\begin{tabular}{|l|c|}
\hline Max thrust & $15.6 \mathrm{kN}$ \\
\hline Fuel consumption & $396.89 \mathrm{~kg} / \mathrm{h}$ \\
\hline SFC & $0.05 \mathrm{~kg} / \mathrm{Nh}$ \\
\hline The degree of compression & $13: 1$ \\
\hline
\end{tabular}

The specific fuel consumption (SFC) was calculated basing on the fuel consumption and the half value of the maximum thrust (the cruise flight use only the half power of engines). Also the source [1] shows the SFC as 0.5 $\mathrm{lb} / \mathrm{lbf} / \mathrm{h}$ and the source [6] shows the SFC as $0.083 \mathrm{~kg} / \mathrm{Nh}$, so after recounting this valuables on the demand units and comparing it with the calculated one from the definition of $\mathrm{SFC}$, the value of SFC was adopted as $0.05 \mathrm{~kg} / \mathrm{Nh}$.

\section{Analysis of flight in windless conditions at FL240}

Calculations of fuel consumption and emission of harmful exhaust gases for windless conditions on the entire route from Rzeszow to Szczecin were made, the results of which provide a certain basis for references for further calculations and analyzes. The analysis includes the climb phase, the cruise phase, the landing phase and all ground operations that are included in the LTO test. The results are presented in the form of diagram in Fig. 3.

According to the results, fuel consumption in the cruise phase constitutes about $70 \%$ of the total fuel consumed during the flight. During the climb phase, fuel consumption is about $12.5 \%$ of the total fuel consumed, and during the approach phase it is about 5\%. Fuel consumption during the LTO test is constant regardless of the phases and amounts to approximately $11 \%$ of the total fuel consumed during the flight. It can be seen that the least fuel is consumed during the approach phase of the aircraft. In the case of analysis of emissions of individual toxic compounds in specific flight phases for different altitudes of aircraft (Fig. 3b), it can be noticed that the largest part of carbon monoxides $(93 \%)$ and nitrogen oxides $(79 \%)$ is emitted during the flight phase because it lasts the longest. The second longest phase is operations included in the LTO test, in which the emission of carbon monoxides accounts for about $15 \%$, while the emission of hydrocarbons in this phase is the largest and constitutes about $28 \%$. a)

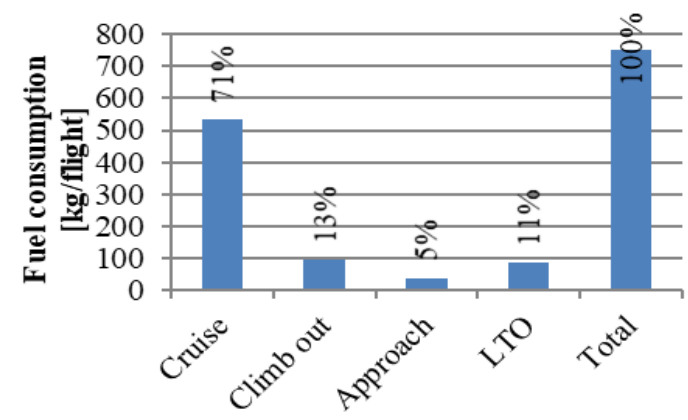

b)

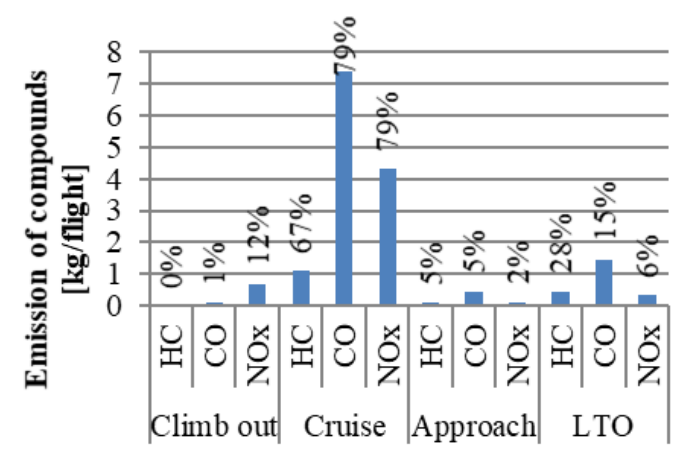

Fig. 3. Results in individual stages of the flight, a) fuel consumption, b) emission of harmful exhaust compounds

\section{Analysis of the cruise phase at FL240}

\subsection{Analysis for low wind speed $(10 \mathrm{kt})$}

Calculations of fuel consumption and emissions of harmful exhaust compounds for different variants of wind speed and direction on one flight level were made. The results are illustrated in the graphs and referred to windless conditions at a given flight level.

a)

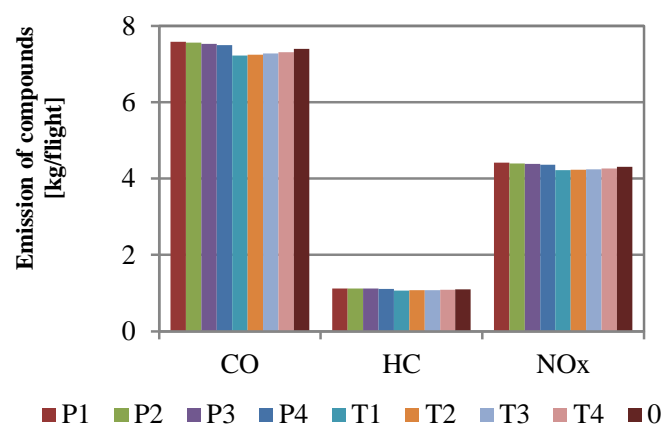

b)

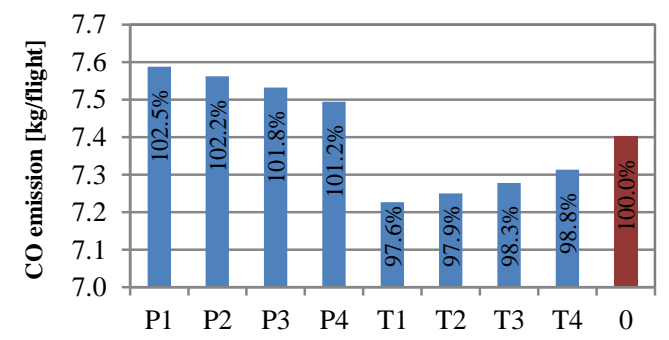

Fig. 4. Emission of harmful exhaust fumes in a given case, a) in general b) emission of carbon monoxides $\mathrm{CO}$ 
a)

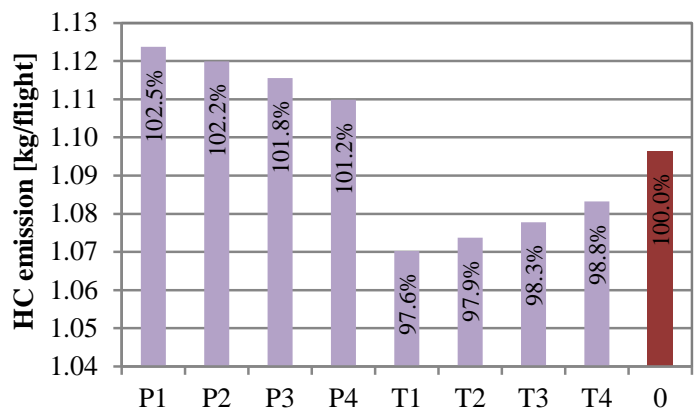

b)

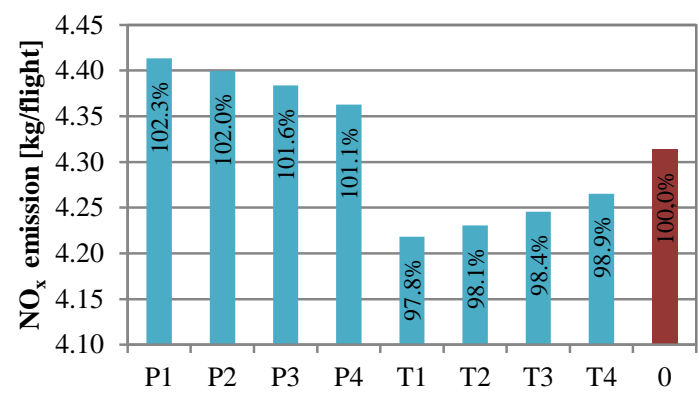

Fig. 5. Emission of harmful exhaust fumes in a given case, a) hydrocarbons $\mathrm{HC}, \mathrm{b}$ ) nitrogen oxides $\mathrm{NO}_{\mathrm{x}}$

The summary chart (Fig. 4a) shows that the differences in the emission of individual harmful compounds between P1-T4 cases are small. The exact percentages can be read from the following charts (Fig. $4 \mathrm{~b}$ and Fig. 5) The difference between the wind that is the most favorable for the flight (T1) and the least favorable wind (P1) is $4.9 \%$ for the emission of carbon monoxides and hydrocarbons in accordance to the emission in still conditions, whereas in the emission of nitrogen oxides the difference is $4.5 \%$. It can also be seen that as the angle of the wind is increased relative to the direction of flight of the aircraft, the emission of toxic compounds slightly decreases with respect to the wind blowing from the front of the aircraft. However, in relation to the wind blowing in the tail of the aircraft, increasing the winding angle causes an increase in the emission of harmful exhaust gases. The most favorable in terms of emissions is therefore the wind blowing from the back of the aircraft, which can reduce the emission of carbon monoxides, hydrocarbons and nitrogen oxides by $2.4 \%, 2.4 \%$ and $2.2 \%$ respectively in relation to the flight in windless conditions. In the case of carbon monoxide, the difference between the most favorable wind and windless conditions is about 0.18 $\mathrm{kg}$ of carbon monoxide per passage. In the case of hydrocarbons, it is about $0.026 \mathrm{~kg}$ per passage, and for nitrogen oxides the difference is about $0.09 \mathrm{~kg}$ per flight.

Analyzing the fuel consumption (Fig. 6a) for the FL240, the same results can be observed as in the case of emissions of individual harmful compounds, i.e. compared to the windless conditions for the wind blowing in front of the aircraft, as the winding angle decreases with respect to the flight direction of the aircraft, the fuel consumption increases, reaching a maximum of $2.38 \%$ more for P1. In the case of wind blowing from the rear of the aircraft, with increasing wind angle relative to the direction of flight, fuel consumption increases, the smallest for wind blowing in the direction of flight, and is $2.27 \%$ less compared to windless conditions, which gives about $12.14 \mathrm{~kg}$ of fuel less. Focusing on the differences in the speed of the aircraft's approaching to the ground (Fig. 6b), it can be also seen about a $2 \%$ drop in speed for wind blowing from the front of the aircraft at different angles, and about $2 \%$ increase in speed for wind blowing in the tail. In the most favorable flight conditions (T1), this speed increases by $2.3 \%$ relative to windless conditions, which gives a ground speed of 816.56 $\mathrm{km} / \mathrm{h}$. These speeds directly affect the flight time between Rzeszow and Szczecin (Fig. 6c) and in the case of T1 allow to shorten the flight by $2.3 \%$ relative to windless conditions, so by 0.9 minutes. Differences between the most favorable conditions (T1) and the least favorable conditions (P1) at the aircraft speed are $4.6 \%$ relative to the windless conditions, which translates into $2.76 \mathrm{~min}$.

a)

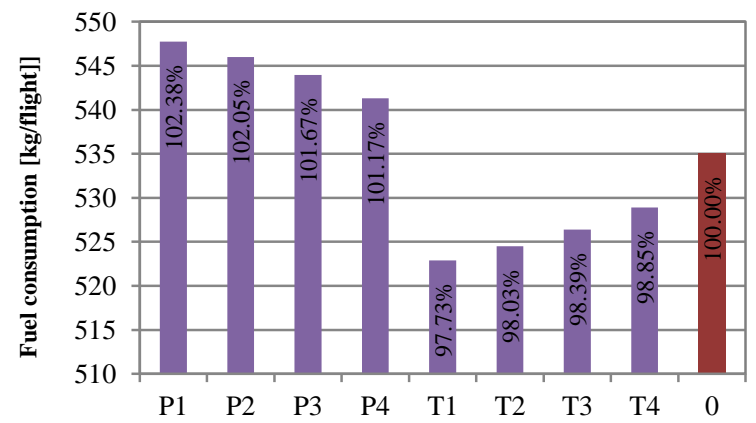

b)

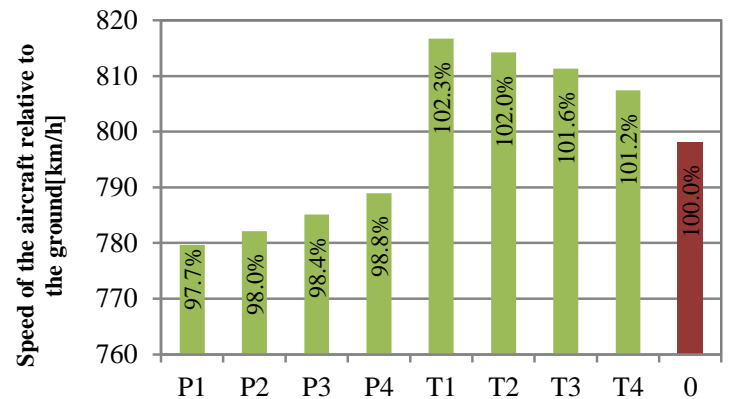

c)

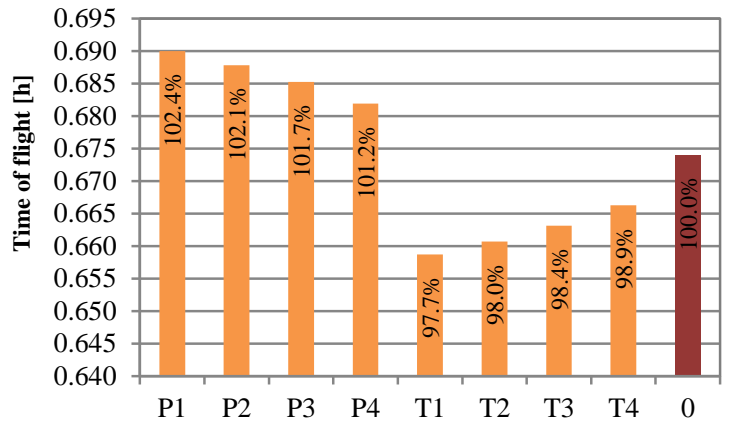

Fig. 6. Analysis of differences in main parameters a) fuel consumption, b) speed of the aircraft relative to the ground, c) flight time

For the analyzed flight level at a wind speed of $10 \mathrm{kt}$, the plane will fly a route from Rzeszow to Szczecin with the least beneficial wind conditions in time $41.4 \mathrm{~min}$ at a speed of $779.68 \mathrm{~km} / \mathrm{h}$ and will use $547.73 \mathrm{~kg}$ of fuel. In the most favorable wind conditions, the aircraft will cover the designated route within 39.54 minutes at a speed of $816.72 \mathrm{~km} / \mathrm{h}$ and consumes $522.89 \mathrm{~kg}$ of fuel. 


\subsection{Analysis for moderate wind speed $(25 \mathrm{kt})$}

Calculations of fuel consumption and emissions of harmful exhaust compounds for $25 \mathrm{kt}$ wind strength and different direction on one FL240 were made. The results are illustrated in the graphs and referred to windless conditions.

a)

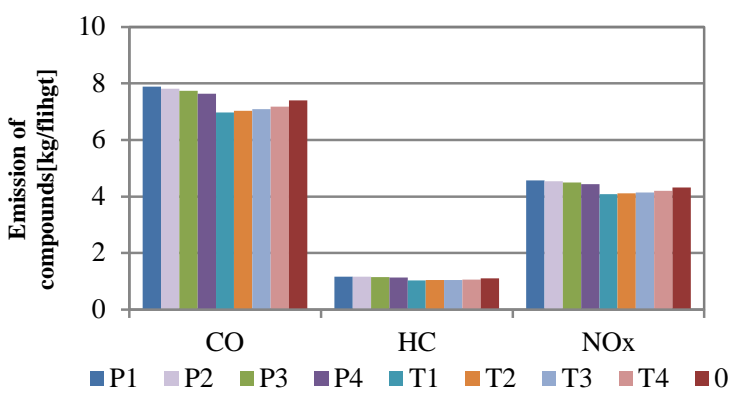

b)

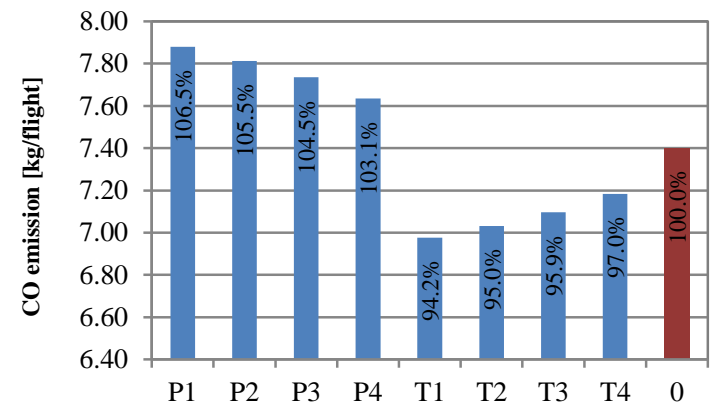

c)

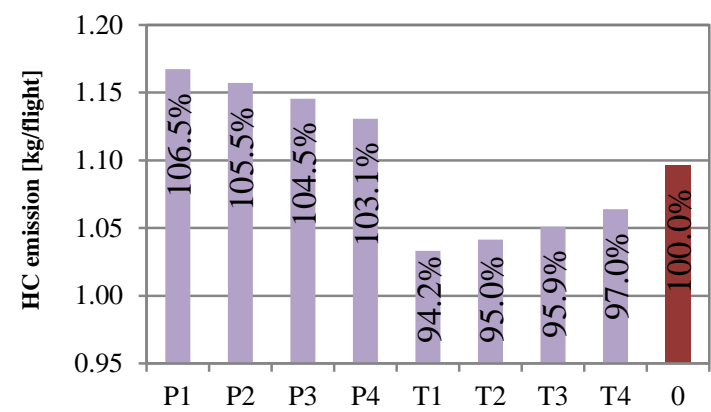

d)

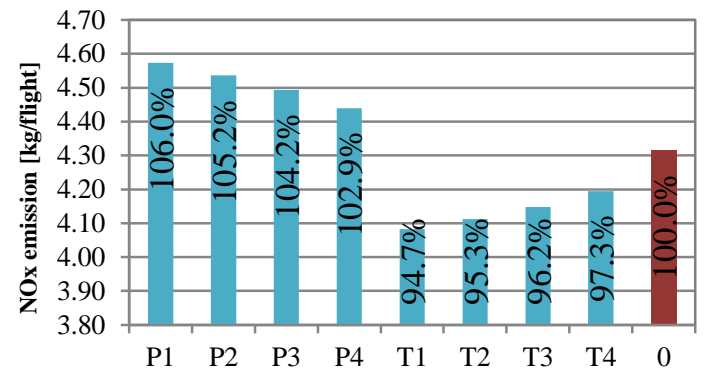

Fig. 7. Emission of harmful exhaust fumes in a given case, a) in general, b) emission of carbon monoxides $\mathrm{CO}$, c) hydrocarbons $\mathrm{HC}$, d) nitrogen oxides NOx

In Figure 7a slight differences between the emission of individual harmful compounds for the variable wind angle were shown. Hydrocarbon emission in each of the analyzed cases is the lowest, and the largest is carbon monoxides. From the following graphs, the exact percentages between the individual variant $\mathrm{P} 1-\mathrm{T} 4$ and the windless conditions can be read.
The difference in the emission of carbon monoxides (Fig. 7b) for the most favorable (T1) and least favorable conditions (P1) is $12.3 \%$ in relation to windless conditions. This gives a difference equal to $0.91 \mathrm{~kg}$ of carbon monoxides. Thus, in the least favorable conditions, the emission of carbon monoxides will be by $0.48 \mathrm{~kg}$ of carbon monoxides more than in the case of windless conditions, while in the case of the most favorable conditions, this emission decreases by $0.43 \mathrm{~kg}$ compared to the windless conditions. The hydrocarbon emission results are similar (Fig. 7c), for which the difference between $\mathrm{P} 1$ and $\mathrm{T} 1$ is also $12.3 \%$ relative to windless conditions, which gives about $0.13 \mathrm{~kg}$. In the case of the most favorable conditions, the aircraft will emit $6.5 \%$ more hydrocarbons, or $0.07 \mathrm{~kg}$ more than in the case of windless conditions, and in the case of the least favorable conditions it will emit $5.8 \%$ less, or $0.06 \mathrm{~kg}$ of hydrocarbons less. Some other percentages take the emission of nitrogen oxides (Fig. 7d), for which the difference between $\mathrm{P} 1$ and $\mathrm{T} 1$ is $11.3 \%$, so it is the smallest in comparison to other harmful compounds. In the case of $\mathrm{P} 1$, the aircraft will emit $6 \%$ more nitrogen oxides than in windless conditions, which gives $0.25 \mathrm{~kg}$. In the case of $\mathrm{T} 1$, the difference is $5.3 \%$ less than in windless conditions, equivalent to $0.23 \mathrm{~kg}$ of carbon monoxides.

Comparing the fuel consumption for the analyzed conditions (Fig. 8a), a $6.2 \%$ difference is visible in the least favorable conditions compared to windless conditions.

a)

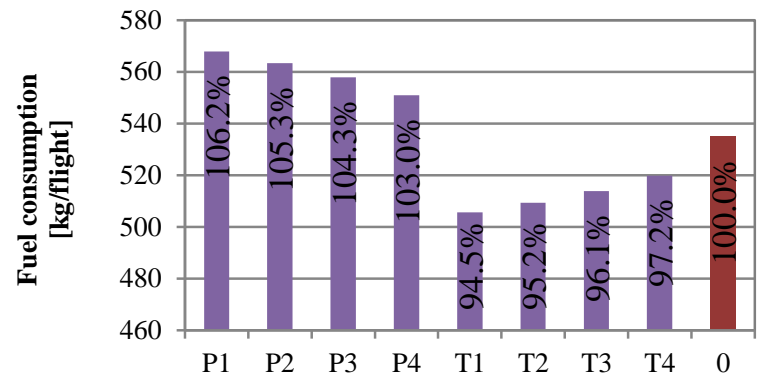

b)

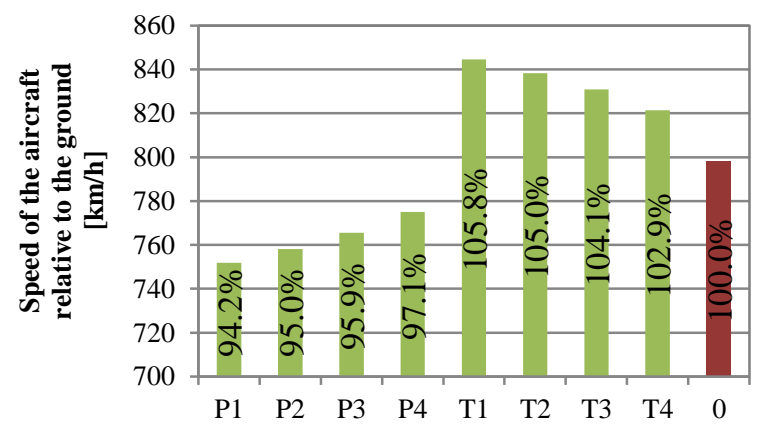

c)

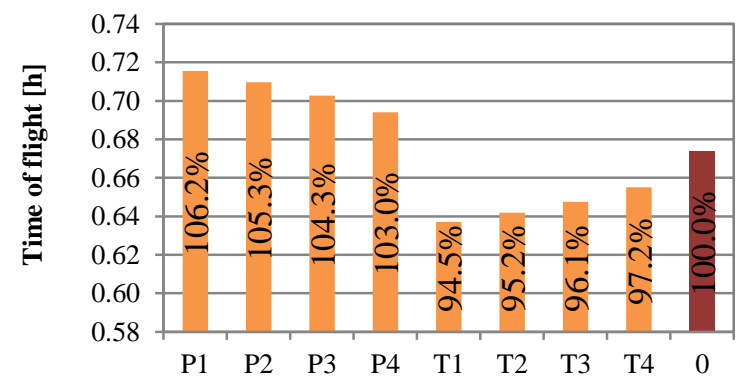

Fig. 8. Analysis of differences in main parameters a) fuel consumption, b) speed of the aircraft relative to the ground, c) flight time 
Means, that the aircraft will use $33.17 \mathrm{~kg}$ more fuel when the wind of moderate speed is blowing from the front of the aircraft. Under the most favorable conditions, fuel consumption will decrease by $5.5 \%$ relative to the windless conditions, which gives $29.4 \mathrm{~kg}$ less fuel than the windless conditions in the case of $\mathrm{T} 1$.

Comparing the change in the ground speed (Fig. 8b) in the case of a change in the wind direction, the aircraft speed decreases by around $1 \%$ with the change of the wind angle from the highest to zero flying from the plane, and the speed increase by about $1 \%$ when changing wind angle from the highest to zero for wind blowing in the direction of flight. The speed of the aircraft will decrease by $5.8 \%$ in the case of $\mathrm{P} 1$ compared to the windless conditions, which gives $46.3 \mathrm{~km} / \mathrm{h}$ less. However, in T1 conditions, this speed will increase by $5.8 \%$, so the aircraft will move by 46.3 $\mathrm{km} / \mathrm{h}$ faster, which shortens flight time (Fig. 8c) by $0.037 \mathrm{~h}$, or about $2.22 \mathrm{~min}$. The flight time of the aircraft varies in proportion to the change in the speed of the aircraft's flight relative to the ground.

\subsection{Analysis for strong wind speed (40 kt)}

When comparing the wind direction change with the highest of the analyzed speeds (40kt) at the FL240 level, it can be noticed that the emission of harmful exhaust compounds (Fig. 9a) is very similar to the wind velocities previously analyzed. In the case of carbon monoxide emissions (Fig. 9b), it is clear that the emission variation for particular wind direction cases is the highest of all wind speeds analyzed.

The difference between P1 and T1 is as much as $19.6 \%$ relative to windless conditions. Under the least favorable conditions, the aircraft will emit by $10.7 \%$ more carbon monoxides than in still conditions, which gives a value equal to $0.79 \mathrm{~kg}$. However, under the most beneficial conditions, it will emit $8.9 \%$ less carbon monoxides than in windless conditions, which gives about $0.66 \mathrm{~kg}$.

Analyzing hydrocarbon emissions (Fig. 9c), one can also notice the greatest variation between individual cases of P1-T4 compared to the previously analyzed wind speeds. In the case of $\mathrm{P} 1$, the hydrocarbon emission will increase by $10.7 \%$ compared to the windless conditions, so by $0.12 \mathrm{~kg}$. In the case of $\mathrm{T} 2$, the hydrocarbon emission will decrease by $8.9 \%$ relative to the windless conditions, which gives about $0.1 \mathrm{~kg}$.

Differences in nitrogen oxide emissions (Fig. 9d) are as follows: $10 \%(0.43 \mathrm{~kg})$ more hydrocarbons for P1 compared to windless conditions, and $8.3 \%(0.35 \mathrm{~kg})$ of hydrocarbons less in T1 case compared to windless conditions.

Analyzing the fuel consumption (Fig. 10a) the difference between $\mathrm{P} 1$ and $\mathrm{T} 1$ is as much as $18.7 \%$, which gives $100 \mathrm{~kg}$ of fuel. Under the most favorable conditions, fuel consumption is $489.58 \mathrm{~kg}$, i.e. $8.5 \%$ less than in windless conditions $(535 \mathrm{~kg})$. However, in the least beneficial conditions, fuel consumption is $10.2 \%$ more, that is by as much as $54.6 \mathrm{~kg}$ more.

Differences in the speed of the aircraft against the ground (Fig. 10b) are also the highest in comparison with the previously analyzed aircraft speeds. In the case of P1, the speed of the aircraft will decrease by $9.3 \%$, while in the case of $\mathrm{T} 1$ this speed will increase by $9.3 \%$, which gives a difference of $74.23 \mathrm{~km} / \mathrm{h}$ depending on the wind direction.

a)

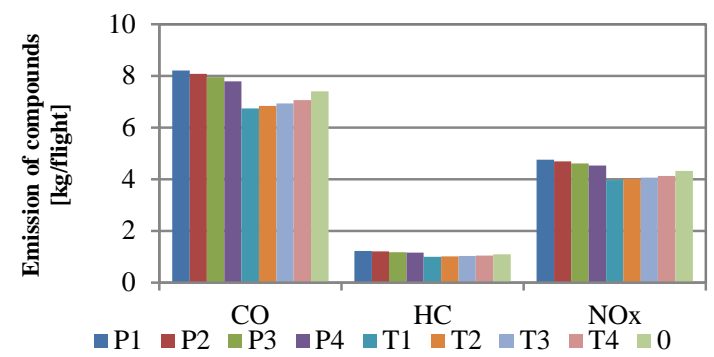

b)

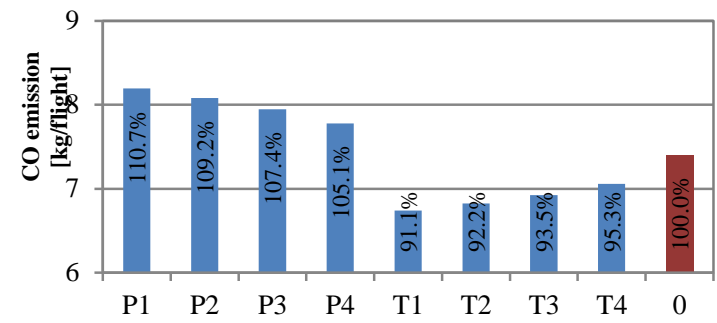

c)

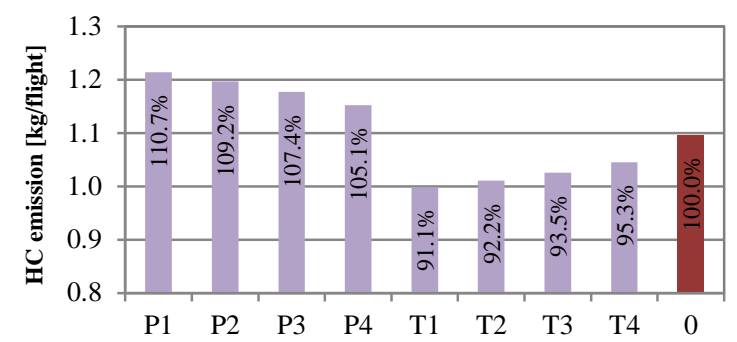

d)

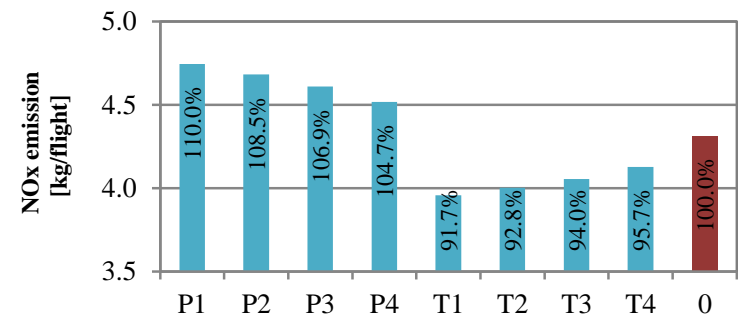

Fig. 9. Emission of harmful exhaust fumes in a given case, a) in general, b) emission of carbon monoxides $\mathrm{CO}$, c) hydrocarbons $\mathrm{HC}$, d) nitrogen oxides $\mathrm{NO}_{\mathrm{x}}$

The flight time of the plane (Fig. 10c) will be $0.617 \mathrm{~h}$ or 37.02 minutes in the most favorable conditions, while in the least beneficial cases it will be $0.743 \mathrm{~h}$, or 44.58 minutes. It is also evident that the flight time of an aircraft increases as the angle at which the wind in the wind blows increases (T1-T4), and that with the increase of the wind angle in relation to the direction of flight of the aircraft (P1-P4) the flight time decreases aircraft.

\section{Conclusions}

In the article influence of wind force and direction on fuel consumption and emission of harmful exhaust gas compounds during the flight were presented. The analysis was carried out for three selected flight levels, in order to compare emissions of harmful exhaust compounds and fuel consumption also depending on the flight level, however the article focuses only on one altitude. The analyzed flight taken place at FL240 on the Rzeszow-Szczecin route with 
Dassault Falcon 100 aircraft, equipped with two Garrett TFE731-2-2B engines.

a)

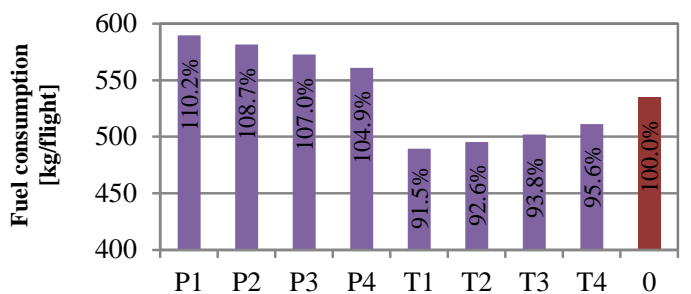

b)

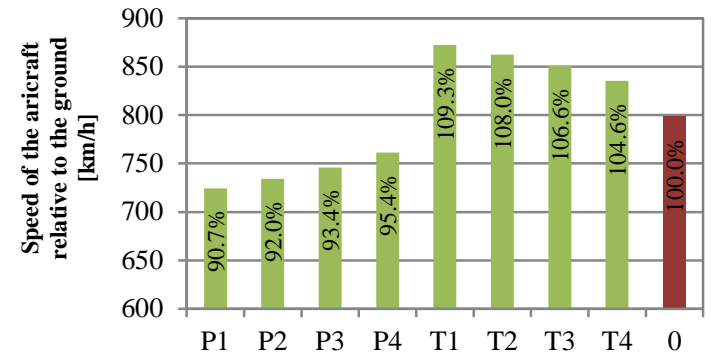

c)

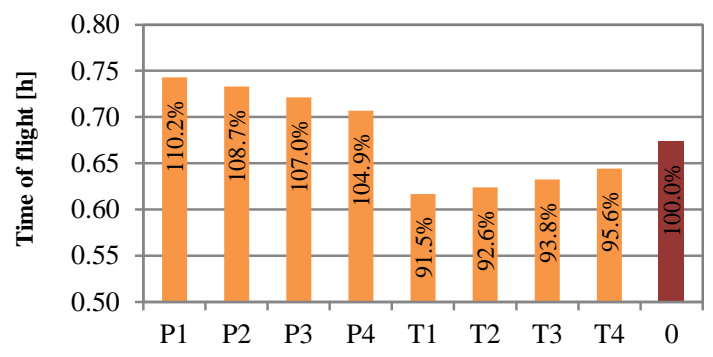

Fig. 10. Analysis of differences in main parameters a) fuel consumption, b) speed of the aircraft relative to the ground, c) flight time
The performed calculations allowed for a percentage comparison of fuel consumption and emissions of individual toxic exhaust compounds depending on the strength and direction of the wind, and in windless conditions. The list of the most favorable calculation results depending on the wind speed compared to windless conditions is presented below (Table 4).

Table 4. Total fuel consumption and emission of harmful compounds for windless conditions and for windy conditions

\begin{tabular}{|c|c|c|c|c|}
\hline Wind & $\begin{array}{c}\text { Fuel consump- } \\
\text { tion [kg/flight] }\end{array}$ & $\begin{array}{c}\mathrm{CO}[\mathrm{kg} / \\
\text { flight] }\end{array}$ & $\begin{array}{c}\mathrm{HC} \\
{[\mathrm{kg} /} \\
\text { flight }]\end{array}$ & $\begin{array}{c}\mathrm{NO}_{\mathrm{x}} \\
{[\mathrm{kg} /} \\
\text { flight }]\end{array}$ \\
\hline No wind & 749.59 & 7.95 & 3.10 & 5.46 \\
\hline Strong tail & 704.15 & 7.29 & 3.00 & 5.10 \\
\hline
\end{tabular}

The comparison shows that at the FL240 flight level, the most favorable fuel consumption and emission of harmful exhaust compounds is achieved by the aircraft during the flight with a wind speed of $40 \mathrm{kt}$ which blows from the tail of the aircraft. The fuel consumption is then reduced by $14 \%$ in relation to the flight with the same wind but blowing from the front of the aircraft, and by $6 \%$ relative to the windless conditions. Also the emission of harmful gas compounds is the smallest when the wind is the strongest from all analyzed speeds of wind, and when this wind is a rear-wind. In comparison to the windless conditions, emission of $\mathrm{CO}$ is $9 \%$ lower when the wind is rear and strong, emission of $\mathrm{HC}$ is $3 \%$ lower and emission od $\mathrm{NO}_{\mathrm{x}}$ is about $7 \%$ lower. That shows, how big impact on fuel consumption and also on emission of harmful gas compounds has the speed and direction of wind, which affect also on the environment.

\section{Nomenclature}

BEM

$\mathrm{CO}$

$\mathrm{CO}_{2}$

$\mathrm{E}_{\mathrm{CO}}$

$\mathrm{EF}$

$\mathrm{E}_{\mathrm{HC}}$

$\mathrm{EI}_{\mathrm{CO}}$

$\mathrm{EI}_{\text {COLTO }}$

$\mathrm{EI}_{\mathrm{HC}}$

$\mathrm{EI}_{\text {HCLTO }}$

$\mathrm{EI}_{\mathrm{NOx}}$

$\mathrm{EI}_{\text {NOxLTO }}$

$\mathrm{E}_{\mathrm{NOx}}$

$\mathrm{EPC}_{\text {pol,app }}$

$\mathrm{EPC}_{\text {pol,climb }}$
Basic Empty Mass [kg]

carbon monoxide

carbon dioxide

carbon monoxide emission $[\mathrm{kg}]$

Emission Factor [lb/1000 lb]

hydrocarbons emission $[\mathrm{kg}]$

emission factor of carbon monoxide $[\mathrm{g} / \mathrm{kg}$ ]

$\mathrm{CO}$ emission factors measured for LTO parameters $[\mathrm{g} / \mathrm{kg}]$

emission factor of hydrocarbons $[\mathrm{g} / \mathrm{kg}$ ]

$\mathrm{HC}$ emission factors measured for LTO parameters $[\mathrm{g} / \mathrm{kg}]$

emission factor of nitrogen oxides $[\mathrm{g} / \mathrm{kg}$ ],

$\mathrm{NO}_{\mathrm{x}}$ emission factors measured for LTO parameters $[\mathrm{g} / \mathrm{kg}]$

nitro gen oxides emission $[\mathrm{kg}]$

emission for a single cycle (EPC) for a particular harmful exhaust gas compound (pol) in a approach phase [lb/cycle]

emission for a single cycle (EPC) for a particular harmful exhaust gas compound (pol) in a climbing phase $[\mathrm{lb} /$ cycle]
$\mathrm{EPC}_{\mathrm{pol} \text {,mode }}$ emission for a single cycle (EPC) for a particular harmful exhaust gas compound (pol) in a specific phase (mode) [lb/cycle]

$\mathrm{EPC}_{\text {pol,takeoff }}$ emission for a single cycle (EPC) for a particular harmful exhaust gas compound (pol) in a taking off phase [lb/cycle]

$\mathrm{EPC}_{\text {pol,taxi }}$ emission for a single cycle (EPC) for a particular harmful exhaust gas compound (pol) in a taxi phase [lb/cycle]

EPC $_{\text {total total emission of a harmful compound }}$ [lb/cycle]

FRR Fuel Flow Rate [lb/hr]

NE Number of engines on the aircraft

$\mathrm{h}$ the air humidity factor depends on the height

$\mathrm{H} \quad$ cruising altitude [ft]

$\mathrm{H}_{1} \quad$ flight altitude [m]

$\mathrm{HC}$ hydrocarbons

ICAO International Civil Aviation Organization

$\mathrm{K} \quad$ engine thrust $[\mathrm{N}]$

$1 \quad$ number of engines [-]

LTO Landing and take-off cycle, model take off and landing cycle used to determine emis- 


\begin{tabular}{|c|c|c|c|}
\hline & $\begin{array}{l}\text { sions of noxious exhaust components of an } \\
\text { aircraft engine }\end{array}$ & $\mathrm{T}$ & $\begin{array}{l}\text { ambient temperature at a given flight alti- } \\
\text { tude }[\mathrm{K}]\end{array}$ \\
\hline Ma & Speed of aircraft $[-]$ & $\mathrm{t}$ & engine run time at a given thrust value [h] \\
\hline MTOW & Maximum Take-off Weight $[\mathrm{kg}]$ & $\mathrm{T}_{\mathrm{c}}$ & total temperature $[\mathrm{K}]$ \\
\hline $\mathrm{NO}_{\mathrm{x}}$ & nitrogen oxides & TIM & Time in Mode [min/cycle] \\
\hline $\mathrm{p}$ & ambient pressure at a given flight altitude $[\mathrm{Pa}]$ & $\delta$ & pressure change coefficient $[-]$ \\
\hline $\mathrm{p}_{\mathrm{c}}$ & total pressure $[\mathrm{Pa}]$ & $\theta$ & temperature change coefficient $[-]$ \\
\hline $\mathrm{PM}$ & particulate matter & $\omega$ & specific humidity $[-]$ \\
\hline $\mathrm{p}_{\mathrm{o}}$ & pressure at a level equal to the sea level [Pa] & & \\
\hline SFC & Specific Fuel Consumption & & \\
\hline
\end{tabular}

\section{Bibliography}

[1] AGARWAL D., The typical takeoff and climb angles of all Boeing planes. Bangalore aviation. 2009, www.bangaloreaviation.com

[2] Airbus, Global Marker Forecast, 2018-2037, www.airbus.com

[3] Business Jet Traveler, www.bjtonline.com (access: 12. 2018).

[4] European Aviation Environmental Report, www.easa.europa.eu.

[5] GALANT, M., KARPIŃSKI, D., MARKOWSKI, J. et al. Comparative analysis of exhaust emission tests for a turbine engine. Combustion Engines. 2015, 162(3), 449-455.

[6] ICAO Engine Exhaust Emissions Data Bank. Technical Library. www.abbottaerospace.com

[7] KUŹNIAR, M., MAJKA, A., PAWLAK, M., PAWLUCZY, J. Analysis of wind impact on emission of selected exhaust compounds in jet engines of a jet aircraft in cruise phase. Rzeszow University of Technology. Rzeszów 2018.

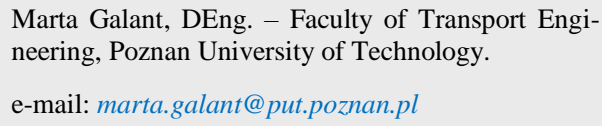

Paula Kurzawska, Eng. - Faculty of Transport Engineering, Poznan University of Technology. e-mail: paula.kurzawska@student.put.poznan.pl
[8] KUŹNIAR, M., MAJKA, A., PAWLAK, M., PAWLUCZY, J. Emission of selected exhaust compounds in jet engines of a jet aircraft in cruise phase. Rzeszow University of Technology. Rzeszów 2018.

[9] KUŹNIAR, M., PAWLAK, M. Problematyka emisji toksycznych składników spalin silników lotniczych. Bezpieczeństwo i ekologia. Autobusy. 2017, 12, 338-344.

[10] MERKISZ, J. Ecology in aviation. Institute of Combustion Engines and Transport, learning materials. Poznan University of Technology. Poznan 2016.

[11] NOWAK, M., JASIŃSKI, R., GALANT, M. Implementation of the LTO cycle in flight conditions using FNPT II MCC simulator, IOP Conference Series: Materials Science and Engineering. 2018, 421.

[12] Wikipedia, www.wikipedia.en

[13] Annex 16 to the Convention on International Civil Aviation, 2008, II. International Civil Aviation Organization.

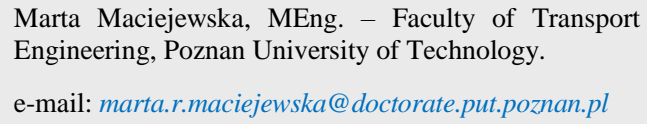

e-mail: marta.r.maciejewska@doctorate.put.poznan.pl

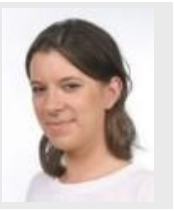

\begin{abstract}
Monika Kardach, MEng. - Faculty of Transport Engineering, Poznan University of Technology.
\end{abstract}

e-mail:monika.t.kardach@doctorate.put.poznan.pl 